\title{
Da memória da utopia: a função autonoética dos programas comemorativos dos 500 anos da publicação de Utopia, de Thomas More, no Reino Unido, França e Portugal
}

The memory of utopia: the reflective function of the commemorations

of the $\mathbf{5 0 0}$ years since the publication of Utopia by Thomas More in the United

Kingdom, France and Portugal

FÁtima Vieira ${ }^{1}$

Resumo: Em 2016, os programas comemorativos dos 500 anos da publicação de Utopia, de Thomas More, lembraram não apenas a vida do humanista inglês, mas também a sua obra. Importa, contudo, percebermos se a memória do passado foi convocada para se compreender o passado (memória intransitiva) ou se foi utilizada para fazer entender melhor o presente e as suas futuras possibilidades (memória transitiva). 0 presente estudo, feito no âmbito dos Estudos de Memória, analisa os programas comemorativos realizados no Reino Unido, França e Portugal, sublinhando a importância da obra de More para a definição da identidade diacrónica de cada uma dessas nações.

Palavras-chaves: Utopia; Estudos de Memória; memória exemplar; lugar de memória; função autonoética; comemoração.

\begin{abstract}
In 2016, the commemorative programmes of the $500^{\text {th }}$ anniversary of the publication of Thomas More's Utopia celebrated not only the life of the English humanist but also his work. It is still to be understood, however, if the memory of the past was summoned to make us better understand the past (intransitive memory) or to make us better understand the present and its future possibilities (transitive memory). This study, made under the theoretical umbrella of Memory Studies, examines the commemorative programmes held in the UK, France, and Portugal, underlining the significance of More's work for the definition of the diachronic identity of those nations.
\end{abstract}

Keywords: Utopia; Memory Studies; exemplary memory; site of memory; autonoetic function; commemoration.

${ }^{1}$ CETAPS — Centre for English, Translation, and Anglo-Portuguese Studies. Faculdade de Letras da Universidade do Porto 


\section{Memórias intransitivas: comemorações em Lovaina}

Visitei, em dezembro de 2016, a cidade de Lovaina, mesmo a tempo de apanhar o momento mais festivo das comemorações dos 500 anos da publicação de Utopia, de Thomas More. ${ }^{2} \mathrm{Da}$ estação de caminho de ferro à Universidade, as ruas anunciavam, com orgulho, que fora ali que, em 1516, na primeira oficina tipográfica da Bélgica, o editor Dirk Martens imprimira a obra-prima de More. Numa extraordinária operação de marketing, os comerciantes haviam adaptado o retrato do humanista inglês, pintado em 1527 por Hans Holbein, o Jovem, aos mais diferentes propósitos - lápis, guarda-chuvas, toalhas de mesa -, enquanto nos bares o nome de More e da sua obra eram convocados para o batismo de cocktails. Ao descer as ruas em direção à Universidade sob o olhar perscrutador do humanista inglês seguindo-me por detrás das vitrinas das lojas, não pude deixar de pensar na forma como a cidade fizera da memória de Thomas More um evento intransitivo.

Foi Tzvetan Todorov quem, num ensaio publicado em 1998 - Les abus de la mémoire defendeu a ideia de que, mais importante do que nos lembrarmos de um evento, é aquilo que fazemos com essa recordação. Segundo o

\footnotetext{
2 Refiro-me ao Leuven Citywide Festival, com um programa que integrou inúmeros eventos que decorreram entre 24 de setembro de 2016 e 17 de janeiro de 2017. Cf. programa em http://www.utopialeuven.
}

filósofo búlgaro, as memórias podem ser convocadas de forma literal ou exemplar. No primeiro caso, assinala-se um evento, mas a evocação é feita de forma intransitiva, já que não há qualquer movimento que vá para além do acontecimento em si. No segundo caso, aquilo que é recordado cumpre uma função instrumental: serve-nos para compreendermos situações novas, com agentes diferentes. A metodologia, neste segundo caso, é a da analogia e generalização. Nas memórias literais, do presente olha-se para o passado; nas memórias exemplares, o passado é utilizado para se compreender (e eventualmente mudar) o presente (Todorov, 1998: 30-31).

Foram naturalmente promovidos em Lovaina eventos de outro tipo, que convidavam à reflexão sobre a época de Thomas More e a influência da sua obra. A exposição no Museu de Lovaina, organizada em parceria com a Universidade, ${ }^{3}$ foi disso exemplo, mas os espetáculos de dança, os concertos de música e as visitas guiadas à cidade sobrepuseram-se à memória da obra do homem que serviu de pretexto à comemoração. Como lembrou Maurice Halbwachs nos estudos sobre a memória coletiva que o celebrizaram nos anos 50 do século $x x,{ }^{4}$

\footnotetext{
3 A exposição dividia-se em quatro temas: 1) Utopia, de Thomas More; 2) A arte, entre o paraíso e o inferno; 3) Horizonte derradeiro; 4) 0 universo. Programa disponível em https://www.mleuven.be/ fr/\%C3\%A0-la-recherche-dutopia.

${ }^{4}$ Refiro-me em particular a La mémoire collective (1950) e a Les cadres sociaux de la mémoire (1925). Embora este último estudo tenha sido publicado pela primeira vez em 1925, em Les
} 
as sociedades não «recordam» nada, no sentido literal, mas possuem uma memória que funciona como a dos indivíduos. ${ }^{5}$ Essa memória coletiva forma a base da identidade coletiva das sociedades e resulta de um processo de seleção de nomes, datas e acontecimentos, a partir dos quais é formada uma narrativa. ${ }^{6}$ Jan Assmann explicaria décadas mais tarde que a memória, quando é convocada para definir a «identidade diacrónica» das sociedades, fornecendo-lhes assim uma «estrutura conectiva», cumpre uma função autonoética (Assmann, 2015: 328). ${ }^{7}$

Travaux de l'Année Sociologique, a teoria da memória coletiva de Halbwachs só viria a captar verdadeiramente a atenção da Academia na década de 50 . Apesar de a crítica mais recente ter vindo a demonstrar algumas insuficiências na teoria de Maurice Halbwachs (cf., por ex., Assmann 2015: 328, que defende a existência de uma «memória comunicativa»), a ideia do sociólogo francês de que as nossas memórias individuais dependem das memórias de outros indivíduos, da nossa família e dos grupos a que pertencemos, é comummente aceite. ${ }^{5}$ Segundo Halbwachs, existe uma relação de solidariedade entre as memórias de um grupo e as memórias individuais: o indivíduo recorda adotando o ponto de vista do grupo; este último, por seu lado, realiza-se e manifesta-se nas memórias individuais (Halbwachs, 1950: VIII).

${ }^{6}$ Halbwachs coloca, a este propósito, uma questão pertinente: «Por que razão fixa a sociedade no tempo pontos de referência espaçados, de forma aliás irregular, uma vez que para certos períodos falta quase tudo, ao passo que em torno de alguns eventos considerados relevantes uma série de outros eventos considerados relevantes se comprimem [...]? Não lhe servem apenas a dividir a duração, mas alimentam-lhe também o seu pensamento» (Halbwachs, 1950: 282). Tradução minha.

70 termo «autonoesis» deriva das palavras gregas autos (auto) e noesis (cognição) e é definido, no âmbito da investigação sobre o cérebro e da teoria da memória, como uma espécie de consciência que condiciona o conhecimento que temos de nós próprios ao longo da nossa duração (Assmann, 2015: 328-329).
A narrativa que a cidade de Lovaina construiu para consumo próprio e para oferecer aos visitantes, em 2016 (e foi literalmente a cidade que a criou, já que envolveu diferentes parceiros, desde a Câmara Municipal à Universidade, passando pelas associações de comerciantes e as escolas), foi a de que foi em Lovaina, na primeira tipografía da Bélgica, muito perto de uma das primeiras universidades da Europa, que foi publicada a primeira edição de Utopia - levada até Dirk Martens, o primeiro editor flamengo, pelo primeiro entre os grandes humanistas europeus: Erasmo de Roterdão. Essa memória não contribuiu, contudo, para uma reflexão sobre uma possível atualização da obra e do pensamento de Thomas More para o século xxı. Na verdade, a evocação da memória de More contribuiu apenas para a disneyficação da cidade, fenómeno que se tem vindo a verificar em muitas cidades europeias tomadas de assalto pela indústria da memória. A memória de More foi, na cidade belga, evocada de forma intransitiva: olhando para 1516 a partir do presente, Lovaina afirmou-se como a cidade onde foi publicada a primeira edição de Utopia. Nada mais. Ponto final.

\section{Utopia como lugar de memória}

Como reiteradamente fez notar Pierre Nora nos estudos que publicou nas décadas de $80 \mathrm{e}$ 90 do século $x x,{ }^{8}$ a memória encontra-se «em

\footnotetext{
${ }^{8}$ Refiro-me aos três espessos volumes que compõem Lieux de mémoire, publicados entre 1984 e 1992. A edição a que recorri para este estudo é 1997, contando com um prefácio de Nora.
} 
permanente evolução, aberta à dialética da recordação e do esquecimento, inconsciente das suas sucessivas deformações, vulnerável à manipulação e à apropriação, suscetível de ficar dormente por longos períodos e ser periodicamente reanimada». É aliás nessa medida que, segundo o autor, ela se distingue da história: a memória «é um fenómeno perpetuamente atual, um laço que nos liga ao eterno presente; a história é a representação do passado» (Nora, 1997a: 21-25). De certa forma, esta definição de memória corresponde à noção de «memória exemplar» (ou «transitiva») de Todorov, mas a intenção de Nora ao oferecer-nos esta definição é outra: o que verdadeiramente importa ao historiador francês é lançar as bases para a ideia de «lugares de memória». Segundo Nora, poderá ser considerado um lugar de memória todo o fenómeno cultural, material, social ou mental que a sociedade associe ao seu passado e à sua identidade nacional. Um lugar de memória poderá ser desde um objeto material e concreto a um objeto abstrato e intelectualmente construído (Nora, 1997a: 15). Mas poderá ser Utopia, de Thomas More, vista como um lugar de memória?

Há um problema prévio, em relação à obra-prima de More, que deverá ser considerado, e que se prende com o facto de o humanista inglês ter criado um neologismo para designar realidades distintas. Na verdade, «Utopia» (literalmente, «não-lugar») é, simultaneamente, o nome da ilha que More imaginou e o título da obra que escreveu. Acresce o facto de o autor, adaptando aos seus propósitos as convenções narrativas da literatura de viagens, ter criado um novo género literário (o género utópico) e dado origem a uma forma de ver e de estar no mundo (o pensamento utópico). «Utopia» é, pois, um termo hoje utilizado para referir quatro realidades diferentes.

Não me parece problemático afirmar que Lovaina fez do livro de More (um objeto material), um lugar de memória, já que - pelo menos em 1516 - foi em torno da produção material da obra do humanista inglês que a cidade definiu a sua identidade coletiva. Contudo, as comemorações dos 500 anos da publicação de Utopia realizaram-se em outros países onde já não a materialidade da obra, mas a utopia enquanto «objeto abstrato» foi recordada e atualizada. Importa, pois, ver de que forma é que esses países fizeram da obra de More um lugar de memória e avaliar se para ela olharam a partir do presente (enquanto evento intransitivo) ou se a convocaram para nela procurarem ferramentas para a compreensão dos nossos tempos - e para a imaginação de um futuro melhor. 


\section{Programas comemorativos no} Reino Unido, França e Portugal: publicações e eventos ${ }^{9}$

Ano de 2016: 85 eventos no Reino Unido; 76 em França; 22 em Portugal. Embora os eventos tenham variado em natureza, tema e duração, os números são expressivos do interesse que a obra de Thomas More continua a suscitar nestes três países. Também o número de livros lançados ao longo de 2016 é revelador: 14 títulos no Reino Unido; 21 em França; 1 em Portugal. Mas o que significam estes números quando articularmos os conceitos de utopia, memória e identidade?

\section{a. Reino Unido}

No país onde Thomas More nasceu, os eventos comemorativos foram, na sua maioria, organizados ou coorganizados por universidades: registaram-se 48 eventos académicos contra 37 eventos de iniciativa não-académica. Embora se tenham realizado eventos em 19 cidades do Reino Unido, foi em Londres que a maioria se concentrou; Lancaster registou também um

\footnotetext{
${ }^{9} \mathrm{~A}$ presente secção parte de um conjunto de dados recolhidos por investigadores e colaboradores do CETAPS sobre eventos organizados e livros publicados sobre a utopia em Inglaterra, França e Portugal no âmbito de um estudo que coordenei e cujos resultados preliminares foram publicados no periódico norte-americano Utopian Studies (cf. Santos, 2017; Vieira, 2017a, 2017b e 2017c). Esse estudo cobriu seis países europeus (Portugal, Espanha, Itália, França, Reino Unido e Irlanda) e ainda a China e Taiwan. A análise que aqui ofereço dos eventos realizados em 2016 é mais detalhada em relação aos três países escolhidos, sendo também original a sua interpretação à luz da função autonoética da memória.
}

número significativo de eventos académicos, ao passo que Bristol se distinguiu pela organização de eventos não-académicos. Do total de 85 eventos realizados no Reino Unido, 23 destacaram-se pela dimensão e impacto: as universidades promoveram seminários, colóquios e congressos, abrindo espaço para a discussão de um espectro alargado de temas, com particular destaque para as questões relacionadas com o ambiente, a sustentabilidade, as alterações climáticas, as energias limpas e a mobilidade. Mas foram sobretudo as exposições e festivais, frequentemente de iniciativa municipal ou associativa (embora alguns eventos tenham beneficiado de parcerias com universidades), que levaram a ideia de utopia até ao público - por vezes literalmente até à rua. «Utopia» serviu de rótulo a concertos, performances teatrais e exposições - os eventos de maior significado assumiram um carácter artístico e cultural. Em Londres, o programa Utopia 2016 - A Year of Imagination and Possibility acolheu um conjunto de iniciativas rotuladas de «utópicas», prometendo «um ano de artistas, designers, provocadores e pensadores fazendo experiências com as formas como poderíamos viver, fazer, trabalhar e como nos poderíamos divertir» (Utopia 2016 - A Year of Imagination and Possibility). ${ }^{10}$ A London Design Biennale - Utopia by Design,

\footnotetext{
${ }^{10}$ Todas as citações de sites estrangeiros foram traduzidas por mim. Todos os sites foram consultados pela última vez a 6 de dezembro de 2017.
} 
que integrava o programa Utopia 2016, levou até Londres «equipas criativas de 40 países e 6 continentes para apresentarem instalações, interrogarem a história da ideia utópica e abordarem e explorarem o papel do design na resolução de alguns dos problemas mais prementes que a humanidade enfrenta» (London Design Biennale - Utopia by Design). Ainda em Londres, o LSE Space for Thought Literary Festival 2016, organizado numa parceria com o Times Literary Supplement, propôs-se «explorar o poder dos sonhos e a imaginação e a importância do idealismo, dissidência, escapismo e nostalgia, bem como os benefícios de se olhar para o mundo de diferentes perspetivas» (LSE Space for Thought Literary Festival 2016). Por seu lado, o Bristol Festival of Ideas procurou respostas para questões prementes:

[...] como poderemos criar uma utopia no século Xxı? Como poderão exemplos do passado de pensamento utópico [...] ensinar-nos sobre a utopia de hoje e para o futuro? Quem decide o que poderá ser uma boa utopia? O que pode oferecer a tecnologia? Será que a ameaça de mudanças climáticas vai trazer novas utopias?» (Kelly, 24 de maio de 2016).

O programa comemorativo foi pontuado pela publicação de 14 livros - um número surpreendentemente reduzido, tendo em conta a dinâmica do mundo editorial britânico. ${ }^{11} \mathrm{Ne}$ -

\footnotetext{
${ }^{11}$ Tenho aqui em conta o levantamento feito por João Santos para a revista Utopian Studies (Santos, 2017).
}

nhum dos títulos se destacou pela temática, concentrando-se essencialmente em redor dos temas previsíveis do utopismo literário e da influência do pensamento utópico na arquitetura e no planeamento urbanístico. Sobre Thomas More, nenhum livro crítico ou biográfico foi publicado, tendo-se assinalado apenas o lançamento de uma tradução revista de Utopia, assinada por Robert M. Adams, certamente para dar resposta ao provável aumento de procura da obra do humanista inglês no quadro dos diferentes programas comemorativos.

\section{b. França}

Num estudo que publicou sobre a história da tradução de Utopia em França, Marie-Claire Phélippeau revela que, durante o período do Iluminismo e da Revolução Francesa, foram publicadas mais traduções da obra-prima do humanista inglês do que em qualquer outro período da história de França. Segundo a autora, o fenómeno ter-se-á ficado a dever ao facto de os autores se terem apropriado do texto de More para criticarem o regime vigente em França e promoverem novas ideias políticas (Phélippeau, 2016: 300). A ligação da obra de More e da imaginação utópica à busca concreta de soluções políticas para problemas reais tem, pois, em França longos séculos, tendo a sua essência e intenção sido resumida pelo lema subversivo do período de Maio de 1968 «exigir o impossível». 
Não nos deverá, pois, surpreender que, dos 76 eventos realizados em França, apenas menos de um terço tenha sido de iniciativa exclusivamente académica. Ao contrário do que sucedeu no Reino Unido, o programa comemorativo em França caracterizou-se por uma dispersão e por iniciativas menos articuladas, mas que ainda assim terão tornado visível a utilidade do pensamento utópico. Apesar de se terem registado eventos em 26 cidades francesas, a maior parte das iniciativas concentrou-se em Paris, fazendo com que da capital francesa irradiasse um conjunto poderoso de exigências e interrogações utópicas: sete manifestações, cinco cimeiras, duas petições, várias sessões com a projeção de filmes subversivos e debates - muitos debates - onde se discutiu tudo: a necessidade de resistir, de se encontrar alternativas políticas, a exigência da implementação de uma estratégia de hospitalidade e os direitos das minorias e grupos social e politicamente frágeis, desde os direitos das mulheres aos direitos dos refugiados - não esquecendo os direitos dos animais. Estiveram ainda em foco questões relacionadas com a sustentabilidade (comunidades sustentáveis; agricultura sustentável) e com a incompatibilidade entre o sistema capitalista e o respeito por limites ecológicos. 0 debate francês distinguiu-se ainda pela maneira frontal como inscreveu no horizonte utópico a defesa da busca de alternativas económicas, incluindo a defesa do Rendimento Mínimo
Garantido, tendo o Mouvement Utopia, uma associação de educação popular sem fins lucrativos, sido responsável por muitas destas iniciativas. Foram organizados alguns seminários, colóquios e congressos sobre arte, arquitetura e literatura, mas foi sem dúvida a estratégia utópica, aplicada à resolução de problemas concretos que assolam a França e o mundo, de uma forma global, que sobressaiu dos programas comemorativos franceses.

Esta efervescência utópica viu-se refletida na publicação de um número surpreendentemente elevado de livros. ${ }^{12}$ Entre esses, distinguiram-se quatro publicações com propostas radicais, reclamando «um mundo sem capitalismo», «um mundo sem desemprego», «um mundo sem dinheiro» e «um mundo de insubmissos». Registaram-se ainda dois livros sobre a Europa, um analisando a própria ideia de Europa do ponto de vista utópico e o outro refletindo sobre o papel da cultura como fator de unificação da Europa. Foram também publicados dois livros sobre religião (um sobre o pensamento cristão e o outro sobre o radicalismo do Daesh), quatro livros sobre problemas bem identificados suscitados por questões de género e de ordem ambiental, dois estudos de caso sobre utopias realizadas e quatro livros com reflexões teóricas, por certo úteis para o avanço da área dos Estudos sobre a Utopia, mas que, infelizmente, tratando-se de publi-

\footnotetext{
${ }^{12}$ Cf. Vieira, 2017c.
} 
cações em língua francesa, irão certamente permanecer desconhecidas da maioria dos leitores anglófonos.

Curiosamente, foi em França que a obra-prima do Renascimento inglês mereceu maior atenção. Foram três, os livros relacionados com More e a sua obra publicados nesse país, em 2016: uma nova biografia do autor, a reedição de uma tradução publicada pela primeira vez em 1842 e uma obra epistolar, composta por cartas imaginárias dirigidas a Thomas More, evidenciando a atualidade da estratégia utópica para a resolução dos problemas do nosso tempo.

\section{c. Portugal}

Dos 22 eventos realizados em Portugal, 14 foram organizados pela Academia. Tratou-se essencialmente de congressos de média ou grande dimensão (dois deles foram dois grandes congressos internacionais ${ }^{13}$ ) onde predominou a análise da Utopia de More, da tradição literária que encetou e da cosmovisão que propôs, e que foi uma e outra vez atualizada, ao longo dos últimos cinco séculos. Adicionalmente, os eventos académicos incluíram uma discussão sobre ambiente e sustentabilidade, utopias políticas, arte e arquitetura e uma reflexão sobre o sentido atual da utopia enquanto fé na possibilidade

\footnotetext{
${ }^{13}$ Refiro-me à $17^{\text {th }}$ Conference of the Utopian Studies Society, realizada em Lisboa, e à EurSafe Conference 2016: Food Futures - Ethics, Science, and Culture, realizado no Porto.
}

de uma construção positiva da sociedade. 0 Congresso Internacional do Espírito Santo, realizado em três cidades (Coimbra, Lisboa e Alenquer), inscreveu na sua agenda o propósito de celebrar «a esperança na possibilidade da construção de um futuro mais justo e mais fraterno que institua um mundo melhor», revisitando o «espírito utópico internacional», mas prestando maior atenção ao português, particularmente o informado pela crença joaquimita numa Terceira Idade da História, que serviu de base às Festas do Espírito Santo. 0 pensamento utópico que os participantes no Congresso se propuseram examinar era, pois, o português, com todas as suas «influências e originalidades» (Congresso Internacional do Espírito Santo). Os eventos não-académicos tiveram grande visibilidade, desde o FICIS - Fórum Internacional das Comunidades Inteligentes e Sustentáveis, que convidava à imaginação de um futuro de «smart cities, smart citizens», com particular atenção para o solucionamento de problemas de mobilidade urbana, ao Folio - Festival Internacional de Literatura de Óbidos, que desenvolveu o seu programa em torno da figura de Thomas More e da ideia de utopia. De assinalar também a relevância do ciclo de conferências «Tendênn cias Globais 2120: Os Futuros de Portugal», realizadas na Fundação de Serralves, no Porto - onde se procurou «identificar e discutir megatendências globais nos domínios político, económico, tecnológico e a segurança, e o seu impacto no futuro dos portugueses e da sua 
democracia» (Vasconcelos, 2015) -, bem como dos Encontros do DeVir, que promoveram o debate sobre a utilidade do pensamento utópico num conjunto de cidades do Algarve. Ao contrário do que se passou em França, não se registaram, em Portugal, debates ativistas ou de engajamento político a propósito da comemoração dos 500 anos da publicação da obra de More.

No que toca a publicações, num primeiro momento a identificação de apenas um livro sobre a temática da utopia poderá ser surpreendente, embora possam ser avançadas, a meu ver, pelo menos três razões explicativas do fenómeno: 1) o facto de os membros da Academia portuguesa serem cada vez mais incentivados à internacionalização, o que significa publicar em editoras estrangeiras; 2) o facto de, tendo os congressos decorrido no ano de 2016, as atas desses eventos ou outras publicações deles decorrentes só estarem normalmente prontas um ano mais tarde; 3) o facto de os trabalhos académicos, como teses de doutoramento e dissertações de mestrado não serem habitualmente publicadas por uma editora, sendo antes disponibilizados nos repositórios institucionais.

Valerá contudo a pena mencionar o único título publicado, já que é um bom exemplo da forma como o pensamento utópico é inter- pretado no nosso país. ${ }^{14}$ Em Jogos Olímpicos sob o signo da utopia, Rui Proença Garcia e António Camilo Cunha partem de uma reflexão informada sobre o conceito de utopia, sobre os espaços heterotópicos das Reduções Jesuíticas e sobre a literatura utópica portuguesa (com particular incidência nas visões idílicas de ilhas perfeitas oferecidas pela imaginação literária de Raul Brandão e Vitorino Nemésio) para chegarem à conclusão de que os Jogos Olímpicos reclamam a construção de uma cidade utópica - a cidade olímpica, onde prevaleçam valores como justiça, identidade e hospitalidade. Este exercício de identificação de traços utópicos nos Jogos é levado ao exagero quando os autores analisam os Jogos da Lusofonia à luz do mito do Quinto Império argumentando que através dos Jogos Portugal pretende afirmar o império português, a nível global (Garcia e Cunha, 2016).

Apesar de só se ter registado a publicação de um livro em Portugal durante o ano de 2016, a Academia demonstrou o seu interesse pelo tema da utopia através da discussão de quatro teses de doutoramento e dezassete dissertações de mestrado, tendo a realidade e a história portuguesas pontuado em alguns desses trabalhos académicos. Surpreendentemente, nenhum desses trabalhos definiu como objeto de trabalho principal o utopismo literário;

\footnotetext{
14 Para uma descrição completa das publicações sobre a utopia registadas em Portugal em 2016 cf. Vieira, 2017b.
} 
apesar disso, o pensamento utópico revelou-se um instrumento essencial para a reflexão sobre o papel que as artes, a arquitetura e o planeamento urbano poderão assumir no processo de construção de uma sociedade mais justa.

\section{Três livros, três memórias autonoéticas}

A diferença entre os programas comemorativos dos 500 anos da publicação de Utopia no Reino Unido, em França e em Portugal, bem como entre a forma como esses países inscreveram o pensamento utópico na sua «identidade diacrónica» - para utilizar a terminologia proposta por Jan Assmann -, poderá ser entendida através da comparação de três traduções da obra-prima de Thomas More publicadas em cada uma das nações.

Embora no Reino Unido não tenha sido publicada nenhuma tradução nova de Utopia para a língua inglesa, registou-se o lançamento de uma tradução algo inusitada - não para inglês, mas para «utopiano». Refiro-me à edição de Utopia escrita no alfabeto inventado por Thomas More, preparada pelo Jeremy Deller and Fraser Muggeridge Studio a partir da tabela de correspondências entre o alfabeto utopiano e o alfabeto latino preparada pelo próprio humanista inglês. ${ }^{15}$

15 O alfabeto utopiano surge logo na primeira edição de Utopia, em apêndice, seguido de um poema onde fala a própria ilha da Utopia, afirmando que Utopus fez da «não-ilha» uma ilha. 0 alfabeto é composto por 22 letras, que correspondem praticamente às 23 letras do alfabeto latino (ao «u» e ao «V» latinos corresponde apenas uma letra utopiana). É
0 resultado foi um livro desconcertante, que terá certamente feito sorrir todos quantos levantaram os exemplares gratuitamente disponibilizados aos visitantes da Somerset House. Do início ao fim, caracteres indecifráveis (nem um só caracter reconhecível, nem mesmo na capa!) lembravam ao leitor o carácter ficcional tantas vezes esquecido da obra de Thomas More. Com efeito, os eventos de maior visibilidade realizados no Reino Unido - as exposições e os festivais - celebraram sobretudo a capacidade reflexiva, indagadora, imaginativa, especulativa, inovadora e criativa do ser humano e a importância de se explorar a dimensão do sonho para se conseguir concretizar algo de assinalável no real. Essencialmente através da arte e do design, tidos como os instrumentos mais adequados para a exploração dos novos possíveis, foi oferecido ao público um discurso altamente crítico e denunciador dos problemas do presente, sublinhando-se a urgência de se pensar em alternativas. No Reino Unido, a memória da Utopia articula, pois, a identidade diacrónica britânica com a forma como a nação encara a ficção, efabulação e imaginação como os instrumentos mais eficazes para se desconstruir o presente e testar novas hipóteses para o futuro.

O ano de 2016 também não originou,em França, a publicação de uma nova tradução de Utopia, de Thomas More.Em vez disso, face ao previsível

constituído por símbolos com a forma de círculos, triângulos e quadrados. 
interesse do público suscitado pelos programas comemorativos, a editora Librio reeditou um volume que publicara em 2013. Esse volume incluía a tradução que Victor Stouvenel publicara em 1842, as notas e correções que Marcelle Botigeli fizera em 1982 e um prefácio de 2013, assinado por Claude Mazauric. Esta é, sem dúvida, uma publicação que ilustra bem a função autonóetica que em França cumpre a memória de Utopia: o texto oferecido ao público para a compreensão da figura tutelar do pensamento utópico não foi uma tradução recente, mas a versão em francês que Stouvenel fez da obra de More a partir de uma tradução inglesa (sabe-se que Stouvenel não utilizou como texto de partida o original em latim). Apesar de ostentar erros amplamente diagnosticados, a tradução de Stouvenel foi ainda assim entendida como um texto eficaz, objeto de constante reflexão e renovação de sentidos. Como explica Marie-Claire Phélippeau, no Iluminismo testemunhou-se, em França, um movimento de interesse pela inovação política. Pouco antes da Revolução Francesa, Thomas Rousseau publicara Tableau du meilleur gouvernement possible ou l'Utopie de Thomas Morus (1780). Nesse texto, o tradutor apresentara a ilha da utopia não como um sonho, mas como um modelo para a remodelação da sociedade, e fizera de Rafael Hitlodeu o porta-voz dos ideais revolucionários (Phélippeau, 2016: 30). Embora de forma menos eloquente, a tradução de Stouvenel - a mais utilizada em França até ao final do século $x x$ - inscreveu o livro de
Thomas More numa longa tradição de busca pelas melhores soluções políticas; e o facto de o prefácio desta edição ter sido assinado por Mazauric indica esta tendência interpretativa da Utopia, já que o historiador, membro do Partido Comunista Francês, é especialista no período da Revolução Francesa. ${ }^{16} \mathrm{Na}$ verdade, como concluiu a filósofa Stéphanie Roza a partir do estudo do pensamento de Etienne-Gabriel Morelly, do abade Gabriel Bonnot de Mably e de Gracchus Babeuf, a utopia, nascida enquanto projeto literário, foi-se progressivamente transmutando em França em projeto filosófico, depois em projeto político, e por fim em «utopia comunista», pronta a ser concretizada na sociedade real (Roza, 2013: 30). Assim se compreende o carácter subversivo, contestatário, revolucionário e verdadeiramente programático que adquiriram alguns dos eventos promovidos em França em 2016, o único país onde o debate sobre a ideia de utopia incluiu a discussão sobre a possibilidade de implementação de medidas muito concretas de alteração da ordem social, política e económica nacionais.

O ano de 2016 não serviu tão-pouco de pretexto para o lançamento de mais uma tradução de Utopia para português. A verdade, contudo, é que muito dificilmente surgirá, nos próximos anos, uma nova tradução enquanto

${ }^{16}$ Sobre a forma como o historiador francês articula as ideias de Revolução Francesa e utopia, cf. Mazauric, 2009. 
estiver no mercado a versão magistral e amplamente anotada de Aires Nascimento. ${ }^{17} \mathrm{Pu}$ blicado pela primeira vez em 2006 e reeditado em 2007 e 2015, o volume lançado pela Fundação Calouste Gulbenkian articula, de forma expressiva, a cultura portuguesa e a tradição de pensamento utópico. Esta articulação é em parte feita pelo «Estudo introdutório» assinado por José Vieira de Pina Martins, que inclui uma secção sobre a Utopia de Thomas More e os Descobrimentos Portugueses e uma outra sobre a receção de Utopia em Portugal nos séculos XVI e XVII (pp. 52-90). Lendo o texto de Pina Martins em 2016, o leitor português era recordado de que

[a] personagem de Hytlodeu, navegador e filósofo, só pode [...] ser interpretada de uma única maneira: trata-se objetivamente da homenagem do futuro chanceler de Inglaterra à epopeia dos navegantes lusos de que então falavam os europeus cultos e suscitava a admiração de todos os que sabiam igualmente compreender o alcance científico e civilizacional dos Descobrimentos geográficos. (Martins, 2006: 60)

\footnotetext{
${ }^{17}$ Aires Nascimento foi o responsável pela edição crítica, tradução e notas de comentário. Por vezes estas são de tal forma extensas que ocupam uma parte substancial do livro. A consulta desta versão oferece ao leitor uma oportunidade única da compreensão do contexto em que Utopia foi escrita. 0 volume oferece ainda, para além de um «Estudo introdutório» de Pina Martins, um fac-simile da edição de Utopia publicada na Basileia em novembro de 1518. Cf. Nascimento, 2006.
}

O programa comemorativo dos 500 anos da publicação de Utopia em Portugal desenvolveu-se, com efeito, com a consciência da relação entre a obra-prima de More e a história da nação lusa, tendo servido também de pretexto para recordar e recontextualizar a utopia portuguesa do Quinto Império.

\section{Transformar a memória em significado}

No seu recente livro $A$ boa política, o filósofo brasileiro Renato Janine Ribeiro lembra a polémica que ainda hoje gera a obra-prima de More: «Lê-se a Utopia sem maior dificuldade. Não há problema em compreender o que o autor diz. 0 problema [...] é que não se sabe o que Morus quis dizer nessa obra, tão dissonante de suas outras. Entende-se o que ele diz, não se sabe o que quis dizer» (p.125). Com efeito, embora a interpretação que é hoje mais corrente de Utopia aponte para uma obra subversiva, denunciadora dos paradoxos da vida social, económica e política do dealbar do século XVI, promotora da reflexão sobre a possibilidade de imaginação de alternativas, a verdade é que essa leitura choca com aquilo que conhecemos da personalidade e da vida de Thomas More que as biografias mais recentes não têm deixado de salientar, em particular a feroz perseguição aos seus concidadãos protestantes que ele considerava hereges. ${ }^{18}$

\footnotetext{
${ }^{18} \mathrm{Em}$ grande parte, esta visão negativa de More deve-se ao Livro dos mártires (1563; título original: Acts and Monuments), onde John Foxe relatou as perseguições de que foram vítima os protestantes por parte da Igreja Católica, atribuindo a More
} 
Contudo, independentemente do que poderá ter querido realmente defender Thomas More, o que nos importa hoje é o seu legado - a ideia de utopia e a forma como frutificou ideologias e abriu novos horizontes.

Lembra Pierre Nora que «é o presente quem cria os seus instrumentos de comemoração, que corre atrás das datas e das figuras a comemorar, que as ignora ou as multiplica [...], mas para as transformar em significado» (Nora, 1997b: 4696). Embora os programas comemorativos dos 500 anos da publicação de Utopia no Reino Unido, em França e em Portugal tenham sido desenhados a considerável distância da vida e da obra-prima de Thomas More, a memória da utopia incluiu a consciência da responsabilidade que a ideia de utopia teve na definição da identidade diacrónica de cada uma das nações. Afirmando-se como «um fenómeno perpetuamente atual» - nos termos de Nora - a memória da utopia revelou o seu carácter «exemplar» e «transitivo». Se em Lovaina a Utopia (a obra impressa, material) se afirmou como um lugar de memória para a cidade, o Reino Unido, a França e Portugal transformaram em lugar de memória a própria ideia de utopia, na sua dimensão abstrata. Uma memória inquieta, dinâmica, transformadora - um instrumento para a compreensão do presente e para a prospeção de futuros possíveis para cada uma das nações.

uma quota significativa de responsabilidade. Em «Thomas More and the Heretics: Statesman or Fanatic?», Richard Rex discute a questão com particular lucidez.

\section{Adenda - Gráficos de análise comparativa}

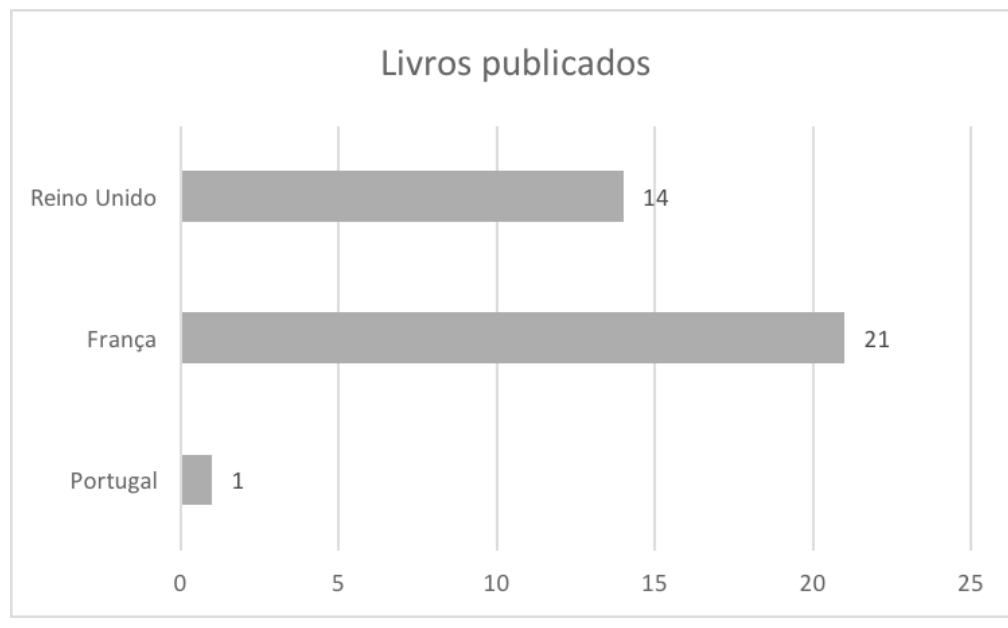

Eventos em 2016

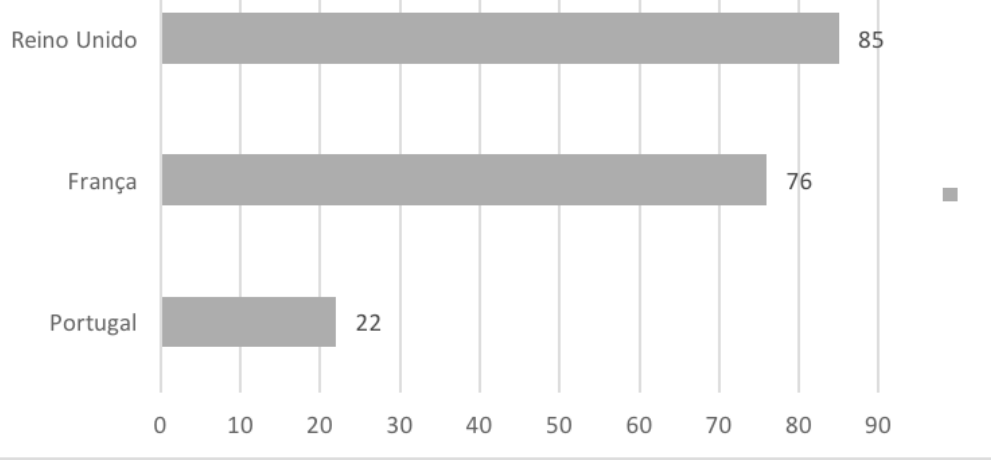

Eventos académicos e não-académicos

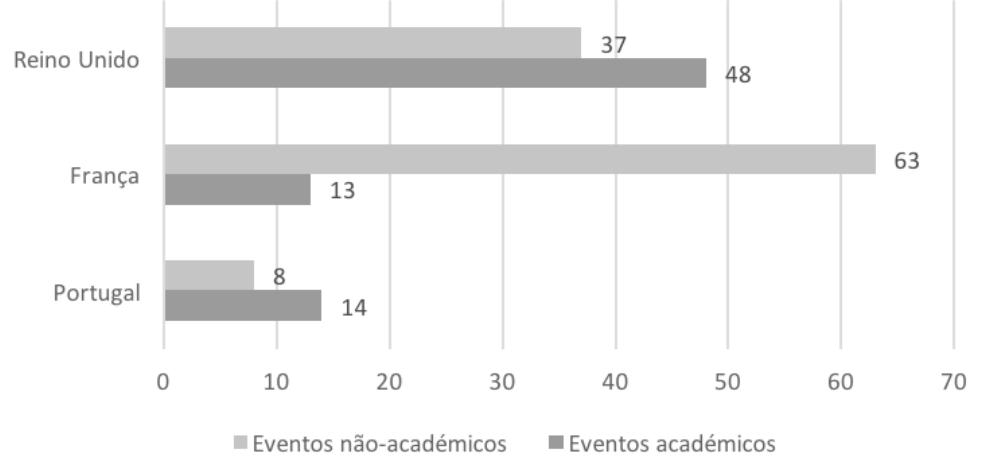

Tipologia dos principais eventos

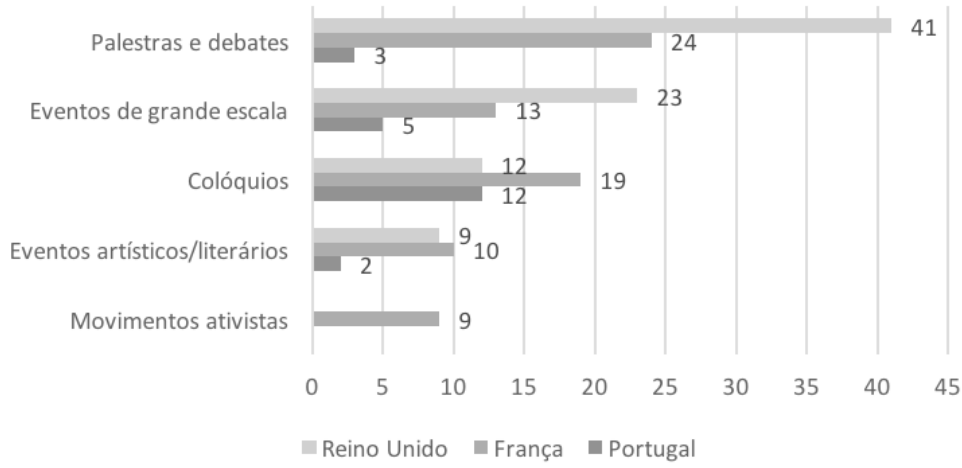




\section{Bibliografia}

\section{Impressa}

Assmann, J. (2015). Memory and Culture. Em: D. Nikulin, Memory: A History. Oxford University Press. Oxford;

Connerton, P. (1989). How Societies Remember. Cambridge University Press. Cambridge;

Deller, J. e Muggeridge, F. (2016). Utopia by Thomas More. Somerset House. London;

Erll, A. (2011). Memory in Culture. Palgrave Macmillan. New York;

Garcia, R.P. e Cunha, A.C. (2016). Jogos Olímpicos sob o signo da utopia. Visão e Contextos. Lisboa;

Halbwachs, M. (1950). La mémoire collective. PUF. Paris;

Halbwachs, M. (1952). Les cadres sociaux de la mémoire. PUF. Paris;

Jeremy Deller and Fraser Muggeridge Studio. (2016). Utopia, by Thomas More (em caracteres utopianos). Somerset House. London;

Martins, J.V. (2006). «Estudo introdutório. Thomas More e a utopia». Em: T. More, Utopia. Fundação Calouste Gulbenkian. Lisboa;

Mazauric, C. (2009). L'histoire de la Révolution Française et la pensée marxiste. PUF. Paris;

Nascimento, A. (2006). Utopia. Fundação Calouste Gulbenkian. Lisboa;

Nora, P. (1989, primavera). Between Memory and History: Les Lieux de Mémoire. Representations. Special Issue: Memory and Counter-Memory. 26: 7-24;

Nora, P. (1997a). Les lieux de mémoire. Quarto - Gallimard. Paris. Vol. 1;

Nora, P. (1997b). Les lieux de mémoire. Quarto - Gallimard. Paris. Vol 3.

Phélippeau, M.-C. (2016). The French Translations of Thomas More's Utopia. Utopian Studies. 27(2): 299-306;

Rex, R. (2011). Thomas More and the Heretics: Statesman or Fanatic? Em: G.M. Logan (ed.),
The Cambridge Companion to Thomas More. Cambridge University Press. Cambridge;

Ribeiro, R.J. (2017). A boa política. Ensaios sobre a democracia na era da Internet. Editora Schwarcz. São Paulo;

Roza,S. (2013). Comment l'utopie est devenue un programme politique: Morelly, Mably, Babeuf, un débat avec Rousseau. Tese de Doutoramento. Departamento de Filosofia em parceria com o Centre d'Histoire des Systèmes de Pensées Modernes (CHSPM). Université de Paris I (Panthéon-Sorbonne). Edição de Autor. Paris;

Santos, J. (2017). Publications on Utopia and Dystopia in the United Kingdom and Ireland. Utopia Studies. 28(3): 652-655;

Todorov, T. (1998). Les abus de la mémoire. Arléa. Paris;

Vieira, F. (2017a). The Year 2016: A Review of the Events Held in Six European Countries. Utopian Studies. 28(3): 587-599;

Vieira, F. (2017b). Publications on Utopian in Portugal (2016 and the First Semester of 2017). Utopian Studies. 28(3): 600-612;

Vieira, F. (2017c). Utopia as a Tool for Change: A Review of Publications on Utopia in France (2016 and the First Semester of 2017). Utopian Studies. 28(3): 624-636.

\section{Digital}

$17^{\text {th }}$ Conference of the Utopian Studies Society. Acedido a 6 de dezembro de 2017, em: http:// uss2016.fcsh.unl.pt/;

À la recherche d'utopia. Acedido a 6 de dezembro de 2017, em: https://www.mleuven. be/fr/\%C3\%A0-la-recherche-dutopia;

Congresso Internacional do Espírito Santo: Génese, Evolução e Atualidade da Utopia da Fraternidade Universal. Acedido a 6 de dezembro de 2017, em: http://www.congressoespiritosanto. net/ptg/index.html;

EurSafe Conference 2016: Food Futures Ethics, Science, and Culture. Acedido a 6 de dezembro de 2017, em: http://www.ibmc.up.pt/ eursafe2016/; 
Kelly, M. (24 de maio de 2016). Utopia Weekender. Acedido a 6 de dezembro de 2017, em: http://www.ideasfestival.co.uk/blog/bristol8 00/utopia-weekender/;

Leuven Citywide Festival. Acedido a 6 de dezembro de 2017, em: http://www.utopialeuven.be/en;

London Design Biennale - Utopia by Design. Acedido a 6 de dezembro de 2017, em: http:// www.londondesignbiennale.com/;

LSE Space for Thought Literary Festival 2016. Acedido a 6 de dezembro de 2017, em: http:// www.lse.ac.uk/Events/LiteraryFestival/2016 ;
Mouvement Utopia. Acedido a 6 de dezembro de 2017, em: http://mouvementutopia.org/ site/;

Utopia 2016 - A Year of Imagination and Possibility. Acedido a 6 de dezembro de 2017, em: http://utopia2016.com/;

Vasconcelos, A. (2015). Ciclo de Conferências: Tendências Globais 2120: Os Futuros de Portugal. Acedido a 6 de dezembro de 2017, em: https://www.serralves.pt/pt/actividades/ ciclo-de-conferencias-temdencias-globais-2030-os-futuros-de-portugal/. 